\title{
Uma reflexão sobre relações grupais a partir da obra psicanalítica de Freud
}

\section{A reflection on group relationships from Freud's psychoanalytic work}

\author{
ANDRESSA ALINE BERTOLLA \\ MÁRCIA CAROLINE SZMID ${ }^{2}$ \\ MICHAELLA CARLA LAURINDO 3
}

\begin{abstract}
Resumo: O presente trabalho propõe uma reflexão acerca das relações que se estabelecem entre as massas e grupos no processo civilizatório, enfocando na formação e funcionamento dos fenômenos grupais. De acordo com Freud ([1930] 2006d), para que seja possível viver em civilização de maneira favorável, os sujeitos não podem satisfazer suas pulsões, mas ao contrário, tendem a reprimi-las ou encontrar destinos que sejam aceitos socialmente. A presente discussão embasa-se na obra psicanalítica de Sigmund Freud, em especial os textos "Psicologia de grupo e a análise do ego" ([1921] 2006c), "O mal-estar na civilização" ([1930] 2006d) entre outros. Freud ([1930] 2006d) revela que o homem é um ser essencialmente agressivo, em herança aos seus antepassados, havendo uma grande inclinação a descarregar a agressividade em direção ao outro e causar-lhe sofrimento. Em "Psicologia de grupo e a análise do ego", o mesmo autor ([1921] 2006c) mostra como os indivíduos agem em massa de maneira distinta de como agiriam se estivessem sozinhos, porque estando em grupos, as forças e impulsos inconscientes prevalecem sobre a personalidade consciente; os sujeitos perdem o senso de responsabilidade e criticidade. Para a psicanálise, um grupo surge por meio de uma relação simbólica entre seus integrantes, que tentam, de forma imaginária, tamponar a castração por meio de um modelo. Esta pesquisa leva-nos ao questionamento de como viver em sociedade relacionamentos interpessoais harmoniosos, quando isto exige de seus membros tantas renúncias pulsionais.
\end{abstract}

Palavras-Chave: Massas. Fenômeno Grupal. Civilização. Satisfação Pulsional. Psicanálise.

Abstract: The present work proposes a reflection on the relations that are established between masses and groups in the civilizational process, focusing on formation and operation of the group phenomena. According to Freud ([1930] 2006d), in order for it to be possible to live in a civilization in a favorable way, subjects cannot satisfy their drives, but on the contrary, they tend to suppress them or find endings that are socially acceptable. The present discussion is based on the psychoanalytical work by Sigmund Freud, notably the texts "Group psychology and the analysis of the ego" ([1921] 2006c), "Civilizations and its discontents" ([1930] 2006d), among others. Freud ([1930] 2006d) reveals that man is an essentially aggressive being, a heritage from its ancestors, there existing a big tendency to unload this aggressiveness onto the other and inflict suffering. In "Group psychology and the analysis of the ego" ([1921] 2006c), the author shows how individuals act in masses in a distinct way from how they would act if they were alone, because by being in a group, the unconscious forces and drives outweigh the conscious personality; the subjects lose their sense of responsibility and critical thinking. In psychoanalysis, a group emerges from a symbolic relationship between its members, who try, in an imaginary way, to obstruct castration through a paragon. This research leads us to the question of how it's possible to live in a society with harmonious interpersonal relationships, when this demands from its members to give up so many of their drives.

Keywords: Masses. Group Phenomenon. Civilization. Drive Satisfaction. Psychoanalysis.

\footnotetext{
${ }^{1}$ Pontifícia Universidade Católica do Paraná. E-mail: dessaaline2@gmail.com

${ }^{2}$ Pontifícia Universidade Católica do Paraná. E-mail: carolszmid@hotmail.com

${ }^{3}$ Professora na Pontifícia Universidade Católica do Paraná. E-mail: michaella.laurindo@pucpr.br
} 


\section{As relações grupais}

O estudo científico aprofundado sobre a noção e formação dos grupos na sociedade vem sendo construída há muito tempo e em diversas áreas, como na sociologia, filosofia, e na própria psicologia, pelos mais diversos enfoques. Na busca para contribuir com este estudo, o presente artigo aborda a noção e formação de grupos na sociedade sob a teoria psicanalítica de Freud. Em "Psicologia de grupos e análise do Ego" ([1921] 2006c) Freud traz a discussão de que antes de uma psicologia individual, há uma psicologia coletiva, "[...] desde o começo, a psicologia individual, nesse sentido ampliado, mas inteiramente justificável das palavras, é, ao mesmo tempo, também psicologia social" (p. 81).

Somos coagidos a viver em sociedade e inseridos em grupos desde muito pequenos. O primeiro grupo do qual participamos é o da família, depois, passamos pelos grupos da igreja, da escola e assim por diante. Desde que nascemos passamos então a viver em uma civilização, em sociedade. Em "O Mal-Estar da civilização" ([1930] 2006d), Freud define civilização como tudo o que afasta o homem de seu estado de natureza, ou seja, é a soma de realizações e instituições que diferenciam a vida humana atual da de seus antepassados animais, e regulamenta os vínculos dos homens entre si. Para que isso ocorra, a civilização passa a agir como um controle externo sobre os sujeitos. Este controle provoca nos indivíduos um mal-estar decorrente do antagonismo entre as exigências das pulsões e as da civilização.

Viver em civilização exige do homem a renúncia à satisfação pulsional, pois se todos satisfizessem seus desejos, seria impossível viver em uma unidade social, e esse movimento de repressão dos impulsos acaba por prejudicar tanto a vida sexual como a agressividade dos sujeitos, já que segundo Freud, o homem é um ser essencialmente agressivo em herança aos seus antepassados, que lutavam uns com os outros pelo direito à sobrevivência. A essa renúncia, existem diversas formas de imposição; algumas delas são a instiga à amizade e à sublimação, outra forma se dá por meio da religião, que prega como princípios o perdão e o amor ao próximo, e também a justiça, que é responsável por manter a ordem e reprimir as satisfações pulsionais individuais (FREUD, [1930] 2006d).

Observamos nas relações sociais, corriqueiros desentendimentos entre os homens, isso ocorre por conta da tendência à agressão, que ainda se faz presente no interior dos sujeitos, mesmo que de maneira imperceptível (FREUD, [1930] 2006d). Outro fato trazido por Freud, e que nos ajuda a explicitar a agressividade presente nas relações, é a existência de dois tipos de pulsão, que embora sejam o oposto uma da outra, são amalgamadas, sendo elas a pulsão de vida e a pulsão de morte, esta última que tende à autodestruição, agressividade e eliminação. Em "Porque a Guerra?" ([1933] 2006e) Freud traz que: “[...] o instinto de autopreservação certamente é de natureza erótica; não obstante, deve ter à sua disposição a 
agressividade, para atingir seu propósito [...]" (p.o7). Os fenômenos da vida ocorrem então da ação conflitante e mutuamente contrária de ambos.

Observamos, portanto, que a agressividade está presente em todos os sujeitos, e segundo Freud, há neles uma grande inclinação a descarregá-la em direção ao outro e causar-lhe sofrimento. A agressão gera facilidade na coesão entre os membros do grupo, e podemos afirmar que a agressividade constitui a base de toda relação de afeto e amor entre as pessoas (FREUD, 1921). Em "À guisa de introdução ao narcisismo" ([1914] 2006a, p. 113) Freud aponta que "o amor por si mesmo só conhece uma barreira: o amor pelos outros, o amor por objetos", podemos compreender assim, que os laços libidinais de um grupo visam, por um lado, o amor entre os integrantes. $\mathrm{O}$ ódio é despertado nos sujeitos, quando algo exterior fere seu próprio narcisismo, levando o homem à atos de eliminação e destruição daquele que aparece como ameaçador.

Em massa, observa-se com frequência, a emissão de comportamentos agressivos que se distinguem dos normalmente realizados por estas pessoas, quando longes dos demais membros do grupo. Freud, em "Psicologia de grupo e a análise do ego" ([1921] 2006c), traz que isso se justifica pelo fato de que nestes casos, as forças e impulsos inconscientes prevalecem sobre a personalidade consciente do sujeito, e são facilmente manipulados por meio da sugestão. É importante que os indivíduos do grupo tenham algo em comum, como o interesse em um objeto ou uma inclinação emocional semelhante, além do mais, em grupos a emoção potencializase ao máximo. Freud ([1921] 2006c, p. 95), embasando-se nos estudos de McDougall acerca da mente grupal afirma que:

[...] a percepção dos sinais de um estado emocional é automaticamente talhada para despertar a mesma emoção na pessoa que os percebe. Quanto maior for o número de pessoas em que a mesma emoção possa ser simultaneamente observada, mais intensamente cresce essa compulsão automática. O indivíduo perde seu poder de crítica e deixa-se deslizar para a mesma emoção. Mas, ao assim proceder, aumenta a excitação das outras pessoas que produziram esse resultado nele, e assim a carga emocional dos indivíduos se intensifica por interação mútua.

A essa maneira de agir grupal, alia-se a forma das relações entre os indivíduos do mesmo grupo, que para manter a harmonia, fazem as mesmas coisas que os demais. Eles substituem a autoridade da sociedade humana, e o detentor do poder ilimitado torna-se o próprio grupo. A intensificação das emoções e a intimidação causada pelo grupo limitam a atividade mental individual, e aqueles que normalmente possuem inteligência mais elevada, se igualam ao nível dos inferiores; o senso de responsabilidade individual também se vê prejudicado, uma vez que deixam de responder por seus próprios desempenhos - "não sou eu, é o grupo" (FREUD, [1921] 2006c). 
Em massa observa-se uma espécie de regressão do pensamento, este estado de regressão propicia a criação de inimigos que são segregados deste grupo, favorecendo a identificação entre os integrantes semelhantes do grupo. Com a criação do inimigo, cria-se também um ídolo a ser seguido e respeitado, que passa a ocupar o lugar do Pai. Segundo Freud ([1921] 2006c), a identificação é conhecida como a mais remota expressão de um laço emocional. Vindo a desempenhar um papel muito importante no complexo de Édipo, o menino mostra um interesse especial para com seu pai, gostaria de ser como ele e tomar seu lugar, colocando seu pai como seu ideal.

Ocorre uma dissolução da identidade de cada sujeito, pela identificação horizontal entre seus participantes e uma identificação vertical com o líder. Este, é introjetado e passa a ocupar o lugar do ideal do ego e do superego de cada um dos componentes da massa. Freud chama atenção para a idealização que ocorre para com o objeto amado, "o objeto é tratado como o próprio eu do sujeito e que no enamoramento passa para o objeto uma parte considerável de libido narcisista" (Freud, [1921], p. 63). Toda função crítica, exercida antes se esvai, deixando o objeto livre de qualquer exigência, chegando a alcançar o grau de perfeição. Freud observa nesse mecanismo da identificação entre os membros da massa para com o líder, o entendimento para a manutenção das massas.

A massa age como uma unidade viva, seguindo docilmente o líder, que é visto como uma figura paterna idealizada. Todos os sujeitos que compõem o grupo têm sua parcela de amor, que é enviada pelo chefe, os tornando uma fraternidade. Em "Psicologia de grupo e análise do Ego" ([1921] 2006c), Freud revela a existência de um desejo de se submeter a um pai poderoso, levando os homens a terem uma tendência a abdicar de sua liberdade tendo como garantia a proteção desse pai zelador.

Com a dissolução da identidade, o sujeito tem seu comportamento habitual modificado, ficando privado de estabelecer parâmetros internos quanto a como se vê, como vê os outros e a própria realidade externa. As massas tendem a se formar de forma espontânea, por darem espaço para que os sujeitos satisfaçam seus desejos humanos. Observamos desta forma, que os sujeitos utilizam da formação das massas como uma válvula de escape para a vivência de seus desejos e fantasias. Os sujeitos substituem seu ideal de eu pelo da massa, compartilhando hostilidade contra os sujeitos não inseridos na mesma. É perceptível que dentro dos grupos estes sujeitos aceitem apenas os argumentos que venham a fortalecer a ligação estabelecida entre eles.

De acordo com Freud (1921), quanto mais forte for as características em comum dos membros da massa, mais forte serão os laços entre eles. Freud em "Psicologia de grupo e análise do Ego" ([1921] 2006c), levanta a discussão de que os impulsos emocionais e os atos intelectuais de cada indivíduo são tão fracos que 
passam a depender inteiramente de serem reforçados por uma repetição por parte dos outros membros da massa. Essa dependência, segundo ele, faz parte da constituição normal da sociedade humana. "[...] cada indivíduo é governado por essas atitudes da mente grupal que se apresentam sob formas tais como características raciais, preconceitos de classe, opinião pública etc.” (p. 127)

Podemos concluir desta forma que, para a psicanálise, um grupo surge por meio de uma relação simbólica entre seus integrantes, de forma imaginária tentam tamponar a castração por meio de um modelo, nesta relação surge o líder, que encarna um ideal, que segundo Freud (1921) ao eleger um modelo, o sujeito inscreve no aparelho psíquico uma instância mediante a qual medirá seu próprio eu.

Em “Totem e Tabu” ([1920] 2006b), Freud afirma que em cada indivíduo singular, há a existência de uma estrutura trans-individual que se manifesta no contexto grupal, como já indicado no transcorrer deste. As mudanças observadas nas relações sociais contemporâneas se mostram como oportunas para repensar os fundamentos da psicanálise aplicados no campo da sociedade. Esta pesquisa levanos ao questionamento de como viver em sociedade relacionamentos interpessoais harmoniosos, quando isto exige de seus membros tantas renúncias pulsionais.

\section{Referências}

FREUD, Sigmund. [1914]. A guisa de Introdução ao Narcisismo. In: FREUD, S. Edição Standard Brasileira das Obras Psicológicas Completas de Sigmund Freud. Rio de Janeiro: Imago, 2006a. Volume XII.

[1920]. Totem e tabu. In: FREUD, S. Edição Standard Brasileira das Obras Psicológicas Completas de Sigmund Freud. Rio de Janeiro: Imago, 2006b. Volume XIII.

. [1921]. Psicologia de grupo e análise do ego. In: FREUD, S. Edição Standard Brasileira das Obras Psicológicas Completas de Sigmund Freud. Rio de Janeiro: Imago, 2006c. Volume XVIII.

. [1930]. O mal-estar na civilização. In: FREUD, S. Edição Standard Brasileira das Obras Psicológicas Completas de Sigmund Freud. Rio de Janeiro: Imago, 20o6d. Volume XXI.

. [1933]. Por que a guerra? In: FREUD, S. Edição Standard Brasileira das Obras Psicológicas Completas de Sigmund Freud. Rio de Janeiro: Imago, 20o6e. Volume XXII.

Submissão: 10.10.2018 / Aceite: 20.12.2019 